\title{
Adsorption Properties of Gemini and Monomeric Cationic Surfactants on Sandstone and Silica Nanoparticles
}

\author{
Wenjun Xie, Ge Xu, Yancheng Zheng*, Shining Chen, Zhuo Yang, Borui Li \\ College of Chemistry and Environmental Engineering, Yangtze University, Jingzhou, China \\ Email: *zhengycg@163.com
}

How to cite this paper: Xie, W.J., Xu, G., Zheng, Y.C., Chen, S.N., Yang, Z. and Li, B.R. (2018) Adsorption Properties of Gemini and Monomeric Cationic Surfactants on Sandstone and Silica Nanoparticles. Open Journal of Yangtze Gas and Oil, 3, 207-219. https://doi.org/10.4236/ojogas.2018.33018

Received: December 11, 2017

Accepted: July 14, 2018

Published: July 17, 2018

Copyright $\odot 2018$ by authors and Scientific Research Publishing Inc. This work is licensed under the Creative Commons Attribution International License (CC BY 4.0).

http://creativecommons.org/licenses/by/4.0/ (c) (i) Open Access

\begin{abstract}
The surface modification of pore throat by adsorption of surfactants is thought to have a positive effect on water flooding in low and ultralow permeability reservoirs. In this paper, Gemini cationic surfactants, containing 12 and 16 carbon alkyl chains(ethanediyl-1,2-bis(dimethyl dodecyl ammonium bromide) and ethanediyl-1,2-bis(dimethyl cetyl ammonium bromide), referred to as $\mathrm{GC}_{12}$ and $\mathrm{GC}_{16}$ ) and hexadecyl trimethyl ammonium bromide $(\mathrm{CTAB})$ were used as modifying agents to investigate the effects of the surfactant concentration, adsorption time and temperature on static adsorption onto the surface of sandstone and silica nano particles (NPS). The results show that the equilibrium adsorption amount of $\mathrm{GC}_{16}$ on sandstone and NPS is higher than that of $\mathrm{GC}_{12}$ on sandstone and NPS with the same initial concentration of $0.225 \mathrm{mmol} / \mathrm{L}$ in solution at $45^{\circ} \mathrm{C}$. It is found that the adsorption amounts of $\mathrm{GC}_{12}$ and $\mathrm{GC}_{16}$ decrease as the raise of temperature. The adsorption rate of surfactant on sandstone surface is slower than that of NPS. The equilibrium adsorption time of these surfactants on sandstone is $20 \mathrm{~h}$, while the time of NPS is only $2 \mathrm{~h}$. At $55^{\circ} \mathrm{C}$, the static saturation absorption amount of $\mathrm{GC}_{12}$ is $210.56 \mu \mathrm{mol} / \mathrm{g}$ on NPS and $117.67 \mu \mathrm{mol} / \mathrm{g}$ on sandstone, while the amounts of $\mathrm{CTAB}$ on sandstone and NPS under static conditions are 1.18 times and 1.46 times of $\mathrm{GC}_{12}$, respectively. Considering the number of tail chain in a molecule of surfactant, the packing densities of Gemini surfactants on solid surface are higher than that of the single-tail surfactant (CTAB). Therefore, the adsorption rate and amount of surfactant are affected by the specific surface of solid particles, charged density, tail chain number and length of the cationic group.
\end{abstract}

\section{Keywords}

Cationic Surfactants, Gemini Surfactants, Adsorption, Silica Nanoparticles, Sandstone 


\section{Introduction}

The chemical recovery technology for enhanced oil recovery has been developed rapidly due to the depletion of oil resources. Water flooding is one of the main methods in low permeability reservoirs. Surfactant injection as a method of a chemical flooding can enhance oil recovery by reducing the interfacial tension (IFT) between oil and water, forming O/Wemulsions, altering the rock wettability and thus resulting from the adsorption of surfactants on reservoir rock [1] [2] [3]. The adsorption of different surfactants, including anionic surfactant, nonionic surfactant, and zwitterionic surfactant on various solid/water interfaces, has been extensively studied by many authors [4]-[12].

In view of percolation theory of reservoirs, if interfacial tension (IFT) between oil and water is reduced to lower than $0.01 \mathrm{mN} / \mathrm{m}$, the effect of capillary force would become negligible and the trapped oil droplets can mobilize in pore channels [13]. But for IFT between injection fluid and oil beyond this scope, capillary force is not neglected and will seriously affect the flow of oil. In recent years, surfactants and nano composites have been used to alter wettability of reservoirs for augmented injection to improve oil recovery [14] [15] [16] [17]. Hydrophobicity modification on the surface of sandstone and nano materials used to treat pore throat of stratum are favorable for changing the wetting stratum into nearly neutral or neutral wetting and reducing the capillary resistance to achieve the purpose of reducing the injection pressure [18] [19]. William [20] used XPS to identify the adsorption density of CTAB and the shape of the aggregates of the cationic surfactant adsorbed to the muscovite mica/aqueous solution interface to investigate the role of electrostatic interactions on surface aggregation. Rowaida KSK [21] prepared new nano composites as disinfectants and antiseptics in food-processing environments through surface modification of montmorillonite by cationic surfactants. Hou [22] used SEM and microscopic displacement to study mechanisms for wettability alteration of oil-wet sandstone surfaces by different surfactants and the effect of reservoir wettability on oil recovery. Asphaltenes adsorbed on sandstone was greatly reduced by the formation of ion pairs between negatively charged carboxylates of crude oil and quaternary ammonium groups of CTAB. CTAB is more effective than polyoxyethylene octyl phenyl ether and sodium lauryl mono-ether sulfate in altering the wettability of oil wet sandstone surfaces. Cationic surfactants could interact with carboxylic acid groups from crude oil to form ion pairs as a result of the electrostatic attraction [23] [24] [25].

Recently, cationic Gemini surfactant, which is composed of two traditional single-alkyl and mono-hydrophilic surfactants that are connected by a spacer, has been paid much attention to its special structure. Each cationic Gemini surfactant has two positive charges in the molecule, rending superior properties than traditional surfactants, such as the ability of reducing the interfacial tensions, and altering the surface electrical properties of the solid. In recent years, the adsorption of surfactants on solid surfaces, such as soil, silica, montmorillonite, kaolinite, has been reported [26] [27] [28] [29]. Grosmaire et al. [26] used 
calorimetric methods to investigate adsorption process of dodecyl trimethyl ammonium bromide (DTAB) and dimeric surfactants. Their adsorption onto amorphous silica is exothermic, and then the exothermic effect rises during the formation of surfactant aggregates. Especially the variation of enthalpy is more exothermic for the Gemini surfactants than for single tail surfactant DTAB, which indicates that the interfacial aggregate is more compact by the Gemini surfactant. Zana [27] investigated the adsorption of DTAB and cationic Gemini surfactants at silica/solution interfaces. The adsorption amounts of DTABand1,2-bis (dodecyl dimethyl ammonio)-ethane dibromide are 3.5 and $5.4 \mathrm{~mol}$ chain $/ \mathrm{m}^{2}$, respectively, in a word, the adsorption density of dimeric surfactant is 1.54 times that of the single tail surfactant. Qi [28] compared the equilibrium concentration at the maximum adsorption of 1,2-bis(cetyldimethylammonio)-ethane dibromide (16-2-16, or $\left.\mathrm{GC}_{16}\right)$ and $\mathrm{CTAB}$ at $25^{\circ} \mathrm{C}$, The result indicates that the Gemini surfactant 16-2-16 is much more efficient than the corresponding conventional surfactant $\mathrm{CTAB}$ at achieving the maximum adsorption on both kaolinite and Na-montmorillonit. Adsorption of 16-2-16 with two quaternary ammonium head groups onto negative sites of the clay is almost identical to that of conventional surfactants CTAB. However, there are very few reports dealing with the comparative study on adsorption behavior of Gemini surfactants and single chain traditional surfactants on silica nano particles (NPS).

In this study, we investigated the adsorption behaviors of Gemini cationic surfactants and single-head cationic surfactant on solid surface with different specific surface area, such as crushed sandstone and nanometer materials. Single-tailed cationic surfactants $(\mathrm{CTAB})$ and Gemini surfactants $\left(\mathrm{GC}_{12}, \mathrm{GC}_{16}\right)$ were used as the modifying agents to make a contrastive investigated adsorption rate and adsorption amount on sandstone and NPS surface.

\section{Experimental Section}

\subsection{Materials and Instruments}

Hexadecyl trimethyl ammonium bromide (CTAB), dodecyl dimethyl tertiary amine, cetyl dimethyl tertiary amine, sodium dodecyl sulfate (SDS), ethyl acetate, methine Blue, thymol blue, bromocresol green were obtained from Aladdin. Sandstone provided by Henan Oilfield was treated by washing, drying, grinding and sieving, with 60 to 100 meshes $(0.25 \mathrm{~mm}-0.15 \mathrm{~mm})$ and a BET surface area of $5.812 \mathrm{~m}^{2} / \mathrm{g}$, to determine the adsorption of surfactants. Nano-silica (NPS) with a BET surface area of $128.896 \mathrm{~m}^{2} / \mathrm{g}$ was purchased from Nanjing Haitai Nanomaterials Co., Ltd, and used as received. The water used in laboratory was twice the distilled water. THZ-82 water bath thermostat oscillator was used to control the temperature in each test; UV-1100 spectrometer was employed to determine the concentrations of surfactants in the solutions.

The series of cationic Gemini surfactants were synthesized according to our previous study [30]. The $\mathrm{CMC}$ values of $\mathrm{GC}_{16}, \mathrm{GC}_{12}$ and $\mathrm{CTAB}$ at $25^{\circ} \mathrm{C}$ are 0.03 $\mathrm{mmol} / \mathrm{L}, 1.0 \mathrm{mmol} / \mathrm{L}$ and $0.8 \mathrm{mmol} / \mathrm{L}$, respectively. Figure 1 shows the chemical structure of these Gemini surfactants. 


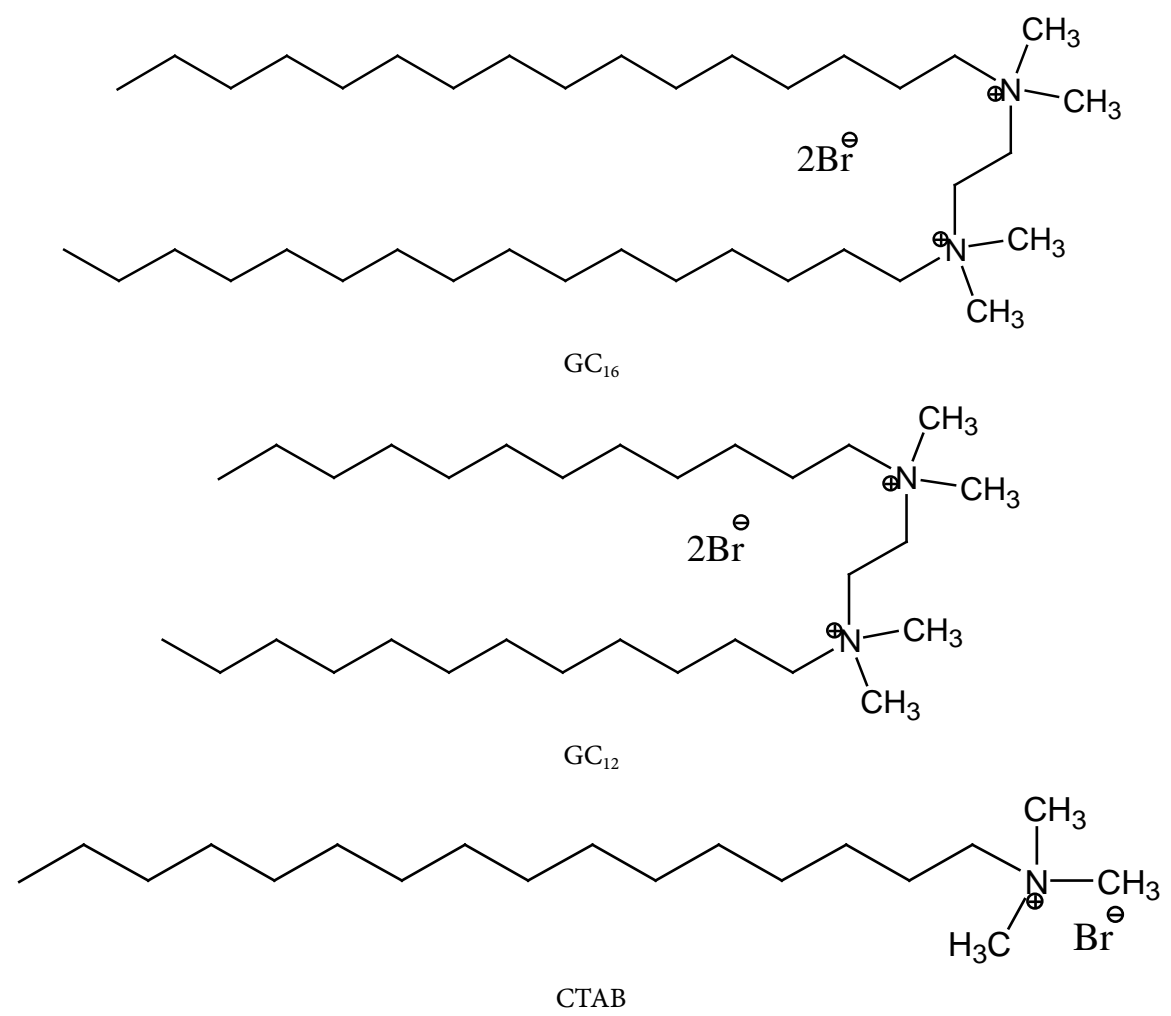

Figure 1. Molecular structure of $\mathrm{GC}_{16}, \mathrm{GC}_{12}$ and CTAB.

\subsection{Determination of Surfactant Concentration}

\subsubsection{Two-Phase Titration Method}

Thymol blue (TB) and bromothymol blue (MB) were equivalently mixed as the compound indicator of water-organic mixtures, then the sample solution of cationic surfactants was titrated with known concentrations of standard anionic surfactant solution were measured to obtain the standard calibration curve [31].

$5 \mathrm{~mL}$ of the standard sodium lauryl sulfate (SDS) solution with the concentration of $1.8 \times 10^{-2} \mathrm{mmol} / \mathrm{L}, 3.6 \times 10^{-2} \mathrm{mmol} / \mathrm{L}$ and $9 \times 10^{-3} \mathrm{mmol} / \mathrm{L}$, respectively, was added into a $100 \mathrm{~mL}$ cylinder with a stopper. $5 \mathrm{~mL}$ of mixed indicator and 5 $\mathrm{mL}$ of sodium sulfate acidic solution were successively introduced into the cylinder, distilled water was then added to obtain $30 \mathrm{~mL}$ of a water phase, followed by $5 \mathrm{~mL}$ of dichloromethane. The mixture in the cylinder was homogenized by vigorous hand shaking. The mixture was titrated with the cationic surfactant solution to be measured till the color of the bottom phase changed from light purple gray to bright yellow green. The color of the upper layer gradually shallowed from pink to colorless. A blank test was conducted to facilitate the comparison. The consuming volume of the cationic surfactant solution was noted to determine the surfactant concentration.

\subsubsection{Spectrometric Method}

The concentrations of surfactant solution lower than $0.01 \times 10^{-3} \mathrm{mmol} / \mathrm{L}$ were determined by the UV spectrometer. The mixture of cationic surfactants with bromocresol green indicator is able to form complexes which can easily dissolve 
in chloroform phase and appears blue. The absorbance of the surfactant solution was determined at a wavelength of $630 \mathrm{~nm}$ when dichloromethane was used as a reference. The linear relationship was drawn between the concentrations of the cationic surfactant and the absorbance of solution as a standard curve. The concentration of sample solution can be obtained from the standard curve of plotting absorbance with concentration of the cationic surfactant.

\subsection{Adsorption Test of Cationic Surfactants}

$0.4 \mathrm{~g}$ (accurate to $\pm 0.0001 \mathrm{~g}$ ) of crushed sandstone or NPS was weighed into a glass tube, followed by adding $8 \mathrm{~mL}$ of surfactant solution. The mixtures were mixed and then kept in the water bath oscillator at $120 \mathrm{r} / \mathrm{min}$ for a period of time at a constant temperature. The tube was taken out and then centrifuged at 3500 $\mathrm{r} / \mathrm{min}$ for $10 \mathrm{~min}$. The supernatant was taken to determine the concentrations of surfactants. The adsorption amount of surfactant on solid particles can be obtained from the surfactant solution concentration change between the initial solution and terminated solution using the following Equation (1).

$$
\Gamma=\frac{\left(c_{0}-c_{\mathrm{e}}\right) V}{m}
$$

where $V$ is the volume $(8 \mathrm{~mL})$ of the solution; $\Gamma$ is the adsorbed surfactants on NPS or sandstone per unit mass, $\mu \mathrm{mol} / \mathrm{g} ; c_{0}$ and $c_{\mathrm{e}}$ are the concentration of the surfactant before and after the adsorption, $\mathrm{mmol} / \mathrm{L}$; and $m$ is the weight of solid particles, $g$.

\section{Results and Discussion}

\subsection{Standard Working Curve}

Standard solutions with different concentrations of cationic CTAB and Gemini surfactant solutions were prepared to measure the absorbance $(A)$. The absorbance $A$ was plotted against the concentration $c$ to obtain the standard curves shown in Figure 2 and Figure 3.

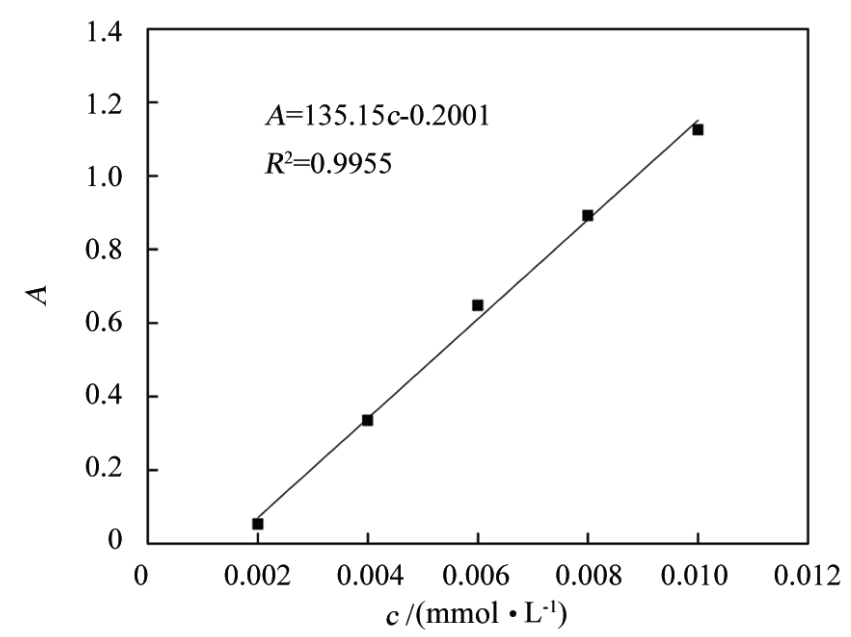

Figure 2. Relation of the absorbance and concentration of CTAB solution. 


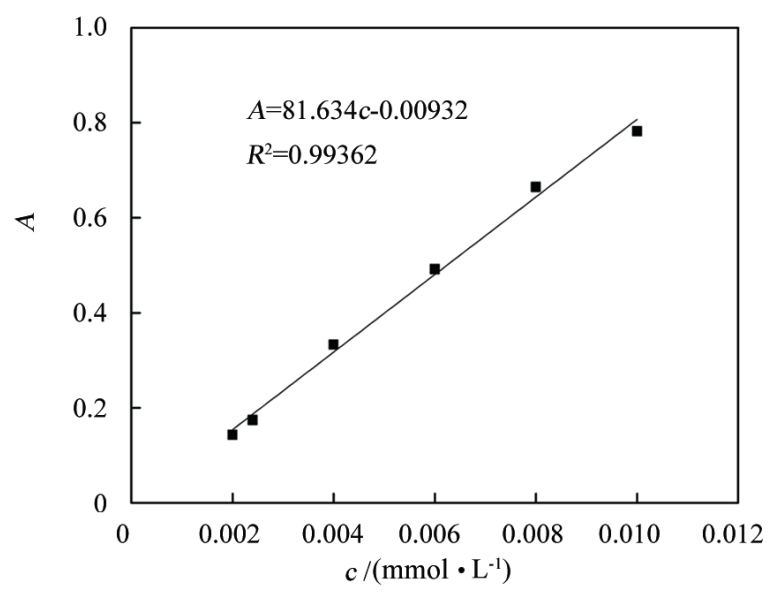

Figure 3. Relation of the absorbance and concentration of $\mathrm{GC}_{12}$ solution.

The results demonstrate that under the experimental conditions, there is a good linear relationship between absorbance $\mathrm{A}$ and $\mathrm{CTAB}$ and $\mathrm{GC}_{12}$ whose concentrations are lower than $0.012 \mathrm{mmol} / \mathrm{L}$.

\subsection{Determination of Adsorption Equilibrium Time}

The highest concentration of $\mathrm{GC}_{16}$ solution that maintained clarification was $0.225 \mathrm{mmol} / \mathrm{L}$ at $25^{\circ} \mathrm{C}$, acting as the initial concentration of the three surfactants for adsorption experiments. This concentration is equivalent to 7.5 times CMC of $\mathrm{GC}_{16}, 0.225$ times that of $\mathrm{CTAB}$, and 0.281 times that of $\mathrm{GC}_{12}$, indicating the initial concentration measured in the experiments is below the CMC values of $\mathrm{CTAB}$ and $\mathrm{GC}_{12}$, and above that of $\mathrm{GC}_{16}$. The adsorption of surfactants in different adsorption time was determined to obtain plots of the adsorption amount of the solution of CTAB, $\mathrm{GC}_{16}$ and $\mathrm{GC}_{12}$ on solid sandstone and NPS surface versus soaked time at $45^{\circ} \mathrm{C}$, as is shown in Figure 4 .

It can be concluded from Figure 3 that the adsorption amount of CTAB, $\mathrm{GC}_{16}$ and $\mathrm{GC}_{12}$ on sandstone surface rapidly increases at $45^{\circ} \mathrm{C}$ with the increase of adsorption time, and then remains constant with time and reach equilibrium after $20 \mathrm{~h}$ of the adsorption on sandstone, while the adsorption equilibrium time of surfactant solution on NPS surface is only $2 \mathrm{~h}$, which indicates that the rate of adsorption of surfactants on NPS is faster to reach equilibrium on the surface of

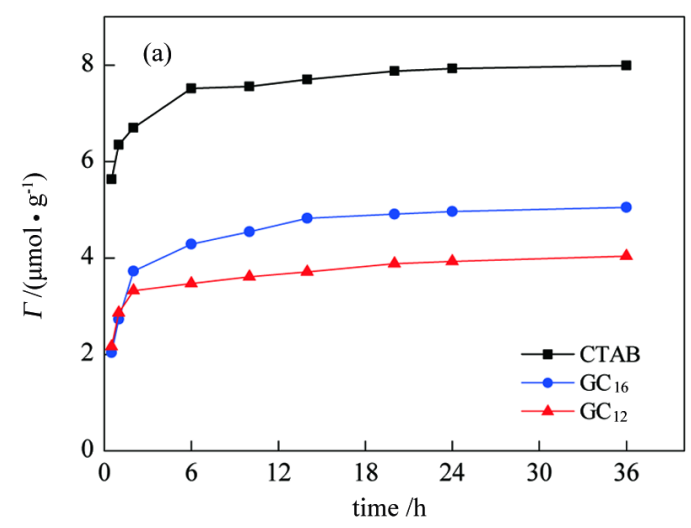




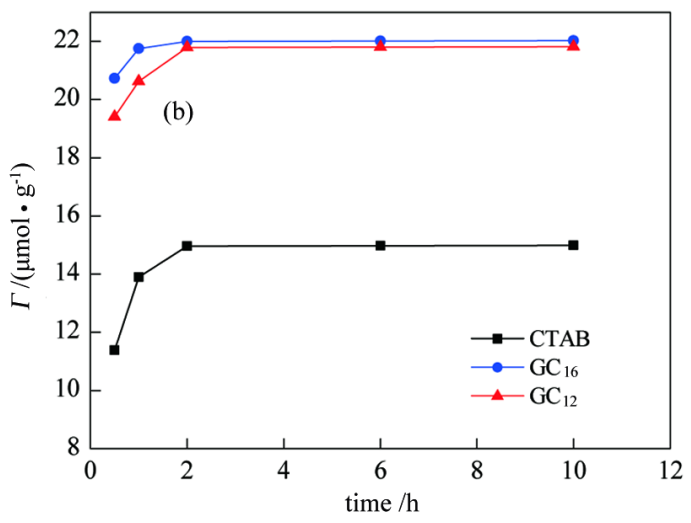

Figure 4. Static adsorption of 3 surfactants on sandstone (a) and NPS (b) vs. time at $45^{\circ} \mathrm{C}$.

sandstone as a result of large specific surface area of NPS.

The adsorption amount of surfactant solution with an initial concentration of $0.225 \mathrm{mmol} / \mathrm{L}$ on both solid surfaces at $45^{\circ} \mathrm{C}$ can be drawn from Figure 3, as shown in Table 1 . The equilibrium adsorption amount of $\mathrm{GC}_{16}$ with double chains and double heads on NPS is $22.01 \mu \mathrm{mol} / \mathrm{g}$, while that of CTAB is 14.96 $\mu \mathrm{mol} / \mathrm{g}$. In a word, the adsorption amount of $\mathrm{GC}_{16}$ is 1.5 times that of single-alkyl CTAB. For crushed sandstone, the adsorption amounts of $\mathrm{GC}_{16}$ and CTAB are $4.91 \mu \mathrm{mol} / \mathrm{g}$ and $7.87 \mu \mathrm{mol} / \mathrm{g}$, respectively, which shows that the adsorption amount of Gemini surfactant $\mathrm{GC}_{16}$ on solid surface is greater than that of the single-chain surfactant CTAB. In addition, it is seen that the maximum adsorption of $\mathrm{GC}_{16}$ on the solid surface including sandstone and NPS is slightly larger than that of $\mathrm{GC}_{12}$, which indicates that the length of hydrophobic alkyl affects the equilibrium adsorption amount, in a word, the adsorption increases with the increase of alkyl carbon number of cationic surfactant molecules with the similarity structure.

Table 1. Equilibrium adsorption amount on sandstone and NPS.

\begin{tabular}{cccc}
\hline surfactant & $\mathrm{CTAB} /\left(\mu \mathrm{mol} \cdot \mathrm{g}^{-1}\right)$ & $\mathrm{GC}_{16} /\left(\mu \mathrm{mol} \cdot \mathrm{g}^{-1}\right)$ & $\mathrm{GC}_{12} /\left(\mu \mathrm{mol} \cdot \mathrm{g}^{-1}\right)$ \\
\hline NPS & 14.96 & 22.01 & 21.79 \\
Sandstone & 7.87 & 4.91 & 3.88 \\
\hline
\end{tabular}

\subsection{Effect of Temperature on the Adsorption}

The surfactant solution with the initial concentration of $0.225 \mathrm{mmol} / \mathrm{L}$ was mixed with a specified mass of particle solid, and immersed in oscillating baths at different temperature for some time, the residual concentration of solution at each time step was determined. When the concentrations of surfactants remain constant with the adsorption time, the adsorption process reaches the equilibrium state. The equilibrium adsorption amounts of the surfactant at $35^{\circ} \mathrm{C}$ $55^{\circ} \mathrm{C}$ were obtained from the trend of the adsorption amount with time, as shown in Table 2. 
Table 2. Equilibrium adsorption amount on sandstone and NPS at different temperatures.

\begin{tabular}{ccccccc}
\hline \multirow{2}{*}{$t{ }^{\circ} \mathrm{C}$} & \multicolumn{2}{c}{$\mathrm{CTAB} /\left(\mu \mathrm{mol} \cdot \mathrm{g}^{-1}\right)$} & \multicolumn{2}{c}{$\mathrm{GC}_{16} /\left(\mu \mathrm{mol} \cdot \mathrm{g}^{-1}\right)$} & \multicolumn{2}{c}{$\mathrm{GC}_{12} /\left(\mu \mathrm{mol} \cdot \mathrm{g}^{-1}\right)$} \\
\cline { 2 - 7 } & sandstone & NPS & sandstone & NPS & sandstone & NPS \\
\hline 35 & 9.06 & 15.40 & 7.29 & 22.36 & 5.49 & 22.16 \\
45 & 7.87 & 14.96 & 4.91 & 22.01 & 3.88 & 21.79 \\
55 & 7.48 & 14.52 & 4.70 & 21.76 & 3.51 & 20.98 \\
\hline
\end{tabular}

It can be seen from the result in Table 2 that the adsorption of surfactant solution with fixed concentration on both solid surfaces decreases with the increasing temperature. At the temperature ranging from $35^{\circ} \mathrm{C}$ to $45^{\circ} \mathrm{C}$, the adsorption amounts of $\mathrm{GC}_{16}$ and $\mathrm{GC}_{12}$ on the sandstone surface decreases by $2.38 \mu \mathrm{mol} / \mathrm{g}$ and $1.61 \mu \mathrm{mol} / \mathrm{g}$, respectively, while the adsorption amounts on the NPS surface decrease by $0.35 \mu \mathrm{mol} / \mathrm{g}$ and $0.37 \mu \mathrm{mol} / \mathrm{g}$, respectively. This is attributed to the fact that the solubility of the ionic surfactant in water increases with the increasing temperature, causing that the affinity of the surfactant with water is enhanced and the tendency to adsorb onto the solid surface is reduced at higher temperature, and thus the adsorption amount is reduced [32] [33]. At the same time, it reveals that the adsorption is an exothermic process and the increasing temperature is favorable for the desorption of surfactants from solid surface. It can also be seen that the adsorption amount of Gemini surfactant $\mathrm{GC}_{16}$ with longer tail is higher than that of $\mathrm{GC}_{12}$.

The adsorption depends on the specific surface area of absence. In the whole range of experimental temperatures $\left(35^{\circ} \mathrm{C}-55^{\circ} \mathrm{C}\right)$, the weaker effect of temperature on the desorption. The adsorption amounts of $\mathrm{GC}_{16}, \mathrm{GC}_{12}$ and $\mathrm{CTAB}$ on NPS surface decrease by $1.11 \%, 1.58 \%$ and $2.86 \%$ respectively, while that on sandstone decrease $17.4 \%, 35.5 \%$ and $36.1 \%$, respectively, indicating that absent adsorption amount of Gemini surfactants on the solid surface decreases slightly compared with that of conventional surfactants. It is well known that the charge density of Gemini cationic surfactants is larger than that of single-alkyl cationic surfactants and nanometer material possess larger specific surface area with more negatively charge on the surface than that of conventional surfactants, so the adsorption capacity of the double-alkyl cations was stronger than that of single-alkyl cations. Each chain of Gemini surfactant molecules adsorbs on silica much more closely than the monomeric surfactant with the same chain length, which is identical to the result reported by Esumi K [34].

\subsection{Effect of Concentration of Surfactant on Adsorption}

$\mathrm{GC}_{12}$ and $\mathrm{CTAB}$ were used to discuss the effect of concentration of surfactants in distilled water on adsorption due to low solubility of $\mathrm{GC}_{16}$ in water. The concentrations of surfactant solutions were measured after being adsorbed for $24 \mathrm{~h}$ on sandstone and NPS at $55^{\circ} \mathrm{C}$, and the static adsorption amount was calculated based on Equation (1). The adsorption isotherms of the two surfactants were illustrated in Figure 5 and Figure 6. 


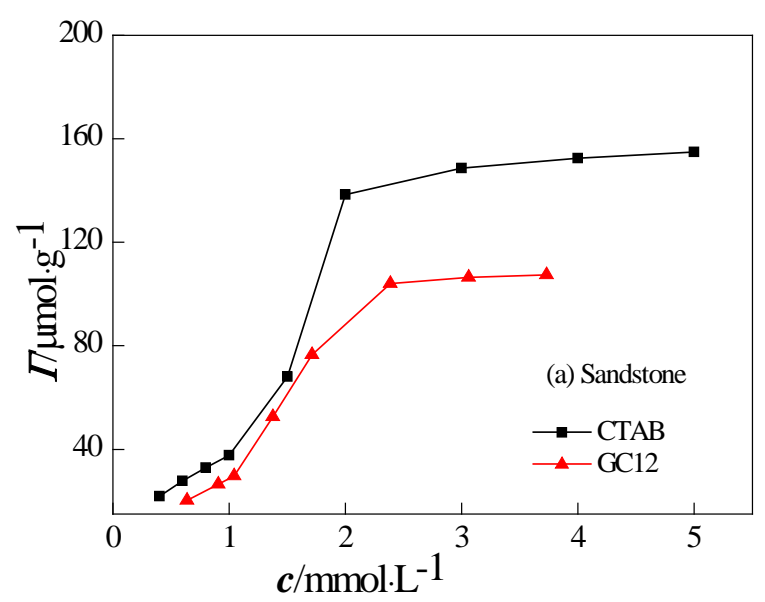

Figure 5. Static adsorption of surfactants on sandstone vs. equilibrium concentration.

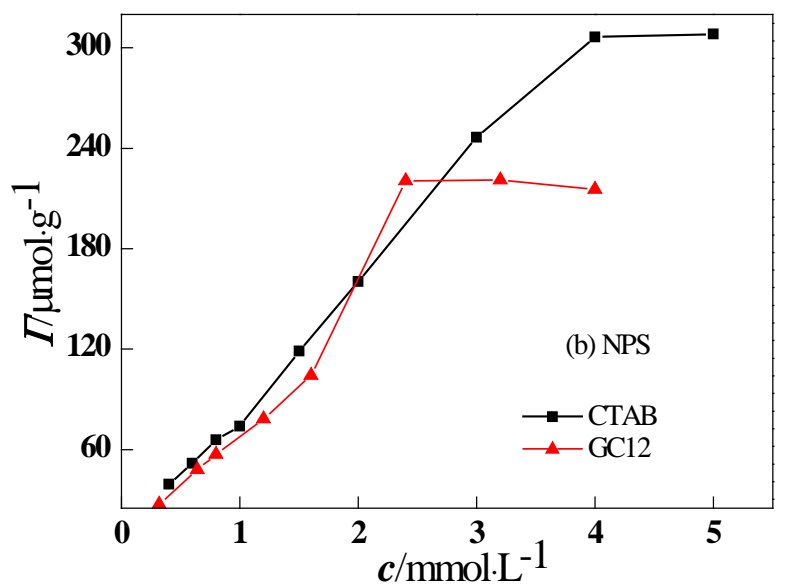

Figure 6. Static adsorption of surfactants on NPS vs. equilibrium of surfactants.

Figure 4 and Figure 5 shows the typical isotherm of adsorption of surfactants in solution on the solid surface in a rather wide range of concentration of surfactants going beyond the CMC. In the first region, the adsorption increases gradually with the concentration. The second region is a sudden increase region of the adsorption due to the lateral interaction between the adsorbed monomer, resulting in the surface aggregation of the surfactants, forming "micelle-like" aggregates or admicelles [7] [35] on the solid surface. The third region shows a slower rate of adsorption. The fourth region is the plateau region of adsorption of surfactants on solid surface basically reaching equilibrium.

It could be seen from the figures that within the experimental concentration range, all four adsorption curves were in consistent with the Langmuir adsorption rule. Due to the different adsorbent properties of each surfactant on sandstone and NPS, the solution concentration to achieve the equilibrium state is different from $\mathrm{CTAB}$ and $\mathrm{GC}_{12}$. The saturated adsorption concentrations of CTAB on sandstone and NPS are $2 \mathrm{mmol} / \mathrm{L}$ and $4 \mathrm{mmol} / \mathrm{L}$, respectively, and the corresponding saturated adsorption amounts are $138.43 \mu \mathrm{mol} / \mathrm{g}$ and $306.46 \mu \mathrm{mol} / \mathrm{g}$, respectively. The saturated adsorption concentration of $\mathrm{GC}_{12}$ on sandstone and 
NPS are both $2.4 \mathrm{mmol} / \mathrm{L}$, and the corresponding saturated adsorptions are $117.67 \mu \mathrm{mol} / \mathrm{g}$ and $210.56 \mu \mathrm{mol} / \mathrm{g}$, respectively, which shows that the adsorption amount in unit of $\mu \mathrm{mol} / \mathrm{g}$ of single-tailed CTAB on sandstone is 1.18 times that of double-tailed $\mathrm{GC}_{12}$ and 1.46 times that of $\mathrm{GC}_{12}$ on NPS.

The adsorption of Gemini surfactant $\mathrm{GC}_{12}$ and traditional cationic surfactant $\mathrm{CTAB}$ on the negatively charged solid surface are driven mainly by the electrostatic interaction between the positive charges in cationic surfactant molecules and negative charges on sandstone and NPS. One $\mathrm{GC}_{12}$ molecule has two cationic heads bonded by a linking group, which would occupy two adsorption sites, while the traditional cationic surfactant CTAB has only one ion head and occupies only one adsorption site. Therefore, the adsorption of CTAB on sandstone and NPS should be twice that of $\mathrm{GC}_{12}$, but in fact it is less than twice that of $\mathrm{GC}_{12}$, which indicts two tails in one molecule of $\mathrm{GC}_{12}$ packing more closely than the conventional single-head and single-tail cationic surfactants and more surfactant molecules detained on the solid surface with negative charge. For conventional cationic surfactants, there exists anlectrostatic repulsion between two adjacent cations when packing on solid-liquid interface, less negative charged points of the solid surface are occupied. So, it is reasonable that the actual adsorption of $\mathrm{CTAB}$ on sandstone and NPS surface is less than twice that of $\mathrm{GC}_{12}$. In addition, the saturated adsorption of $\mathrm{GC}_{12}$ on the NPS surface is 1.8 times that of $\mathrm{GC}_{12}$ on the sandstone surface, which is due to the fact that NPS has a larger specific surface area and a smaller particle size compared with the sandstone.

\section{Conclusions}

The adsorptions of two cationic Gemini surfactants $\left(\mathrm{GC}_{12}\right.$ and $\left.\mathrm{GC}_{16}\right)$ on Henan sandstone with BET specific surface area of $5.812 \mathrm{~m}^{2} / \mathrm{g}$ and NPS with BET specific surface area of $128.896 \mathrm{~m}^{2} / \mathrm{g}$ were studied and compared with that of typical cationic surfactant (hexadecyl trimethyl ammonium bromide, CTAB).

The equilibrium adsorption time depends on the specific surface area of absorbents, the equilibrium time of $\mathrm{CTAB}, \mathrm{GC}_{16}$ and $\mathrm{GC}_{12}$ in fixed concentration solution on NPS is $2 \mathrm{~h}$ at $45^{\circ} \mathrm{C}$, while on the sandstone it is $20 \mathrm{~h}$. The equilibrium adsorption amount of Gemini cationic surfactants with the same spacer group onto the solid surface increases with the increase of hydrophobic carbon number. At $45^{\circ} \mathrm{C}$, the equilibrium adsorption amounts of $\mathrm{GC}_{16}$ and $\mathrm{GC}_{12}$ on the surface of sandstone are $4.91 \mu \mathrm{mol} / \mathrm{g}$ and $3.88 \mu \mathrm{mol} / \mathrm{g}$ respectively, while on the surface of NPS the amounts are $22.01 \mu \mathrm{mol} / \mathrm{g}$ and $21.79 \mu \mathrm{mol} / \mathrm{g}$, respectively, that is to say, cationic surfactants prefer to adsorb onto the solid particles with large specific surface area. The adsorption isotherms on the solid surface are in consistent with the Langmuir adsorption rule. The adsorption decreases weakly with the increasing temperature. The saturated adsorption of Gemini cationic surfactant $\mathrm{GC}_{12}$ on NPS surface is higher than that on the sandstone surface due to the smaller particle size and larger specific surface area of NPS. Although the saturated adsorption amounts of single-chain CTAB on sandstone and NPS surface are 1.18 times and 1.46 times that of $\mathrm{GC}_{12}$, respectively, considering the number 
of tail chain of surfactants, the two alky chains of Gemini surfactants $\mathrm{GC}_{12}$ molecules pack on the solid surface more closely than the single-chain of CTAB molecules.

\section{Acknowledgements}

We gratefully acknowledge financial support by the National Natural Science Foundation of China (51474035) and Project supported by Hubei college students innovative experiment program (20150060).

\section{References}

[1] Michele, M.T., Clouse, J.A. and Longo, J.M. (1993) Adsorption of Organic Compounds on Carbonate Minerals: 1. Model Compounds and Their Influence on Mineral Wettability. Chemical Geology, 109, 201.

https://doi.org/10.1016/0009-2541(93)90070-Y

[2] Hassenkam, T., Pedersen, C.S., Dalby, K. and Austad, T. (2011) Pore Scale Observation of Low Salinity Effects on Outcrop and Oil Reservoir Sandstone. Colloid Surfaces A: Physicochem Eng. Aspects, 390, 179.

[3] Buckley, J.S. (2001) Effective Wettability of Minerals Exposed to Crude Oil. Current Opinion in Colloid \& Interface Science, 6, 191. https://doi.org/10.1016/S1359-0294(01)00083-8

[4] Grosse, I. and Estel, K. (2000) Thin Surfactant Layers at the Solid Interface. Colloid and Polymer Science, 278, 1000. https://doi.org/10.1007/s003960000364

[5] Tiberg, F., Brinck, J. and Grant, L. (2000) Adsorption and Surface-Induced Self-Assembly of Surfactants at the Solid-Aqueous Interface. Current Opinion in Colloid \& Interface Science, 4, 411. https://doi.org/10.1016/S1359-0294(00)00016-9

[6] Somasundaran, P. and Huang, L. (2000) Adsorption/Aggregation of Surfactants and Their Mixtures at Solid/Liquid Interfaces. Advances in Colloid and Interface Science, 88, 179. https://doi.org/10.1016/S0001-8686(00)00044-0

[7] Paria, S. and Khilar, K.C. (2004) A Review on the Experimental Studies of Surfactant Adsorption at the Hydrophilic-Solid Interface. Advances in Colloid and Interface Science, 110, 75. https://doi.org/10.1016/j.cis.2004.03.001

[8] Zhang, R. and Somasundaran, P. (2006) Advances in Adsorption of Surfactants and Their Mixtures at Solid/Solution Interfaces. Advances in Colloid and Interface Science, 123-126, 213. https://doi.org/10.1016/j.cis.2006.07.004

[9] Muhammad, R.A., Tan, I.M., Ismail, L., Muhammad, M., Muhammad, N. and Sagir, M. (2013) Static Adsorption of Anionic Surfactant onto Crushed Berea Sandstone. Journal of Petroleum Exploration and Production Technology, 3, 195. https://doi.org/10.1007/s13202-013-0057-y

[10] von Rybinski, W., Jabnoun, M. and van Megen, J. (2015) Structures of Adsorption Layers of Surfactant Mixtures on Nonpolar Solid Surfaces. Colloid and Polymer Science, 93, 3107.

[11] Manne, S., Cleveland, J.P., Gaub, H.E., Stucky, G.D. and Hansma, P.K. (1994) Direct Visualization of Surfactant Hemimicelles by Forcemicroscopy of the Electrical Double Layer. Langmuir, 10, 4409-4413. https://doi.org/10.1021/la00024a003

[12] Salehi, M., Johnson, S.J. and Liang, J.T. (2010) Enhanced Wettability Alteration by Surfactants with Multiple Hydrophilic Moieties. Journal of Surfactants and Detergents, 13, 243-246. https://doi.org/10.1007/s11743-010-1193-8

[13] Cui, Z.G., Li, W., Qi, J.J. and Wang, H.J. (2012) Individual and Mixed Adsorption 
of Alkylcarboxylbetaines and Fatty Amide Ethoxylates at Daqing Sandstone/Water Interface. Colloids and Surfaces A: Physicochemical and Engineering Aspects, 414, 180-189. https://doi.org/10.1016/j.colsurfa.2012.08.013

[14] Roustaei, A., Saffarzadeh, S. and Mohammad, M. (2013) An Evaluation of Modified Silica Nanoparticles Efficiency in Enhancing Oil Recovery of Light and Intermediate Oil Reservoirs. Egyptian Journal of Petroleum, 22, 427-433.

https://doi.org/10.1016/j.ejpe.2013.06.010

[15] Mohammad, Z., Riyaz, K. and Nasim, B. (2015) Enhancement of Surfactant Flooding Performance by the Use of Silica Nanoparticles. Fuel, 143, 21-27. https://doi.org/10.1016/j.fuel.2014.11.040

[16] Zargartalebi, M., Barati, N. and Kharrat, K. (2014) Influences of Hydrophilic and Hydrophobic Silica Nanoparticles on Anionic Surfactant Properties: Interfacial and Adsorption Behaviors. Journal of Petroleum Science and Engineering, 119, 36-43. https://doi.org/10.1016/j.petrol.2014.04.010

[17] Zargartalebi, M., Kharrat, R., Barati, N. and Zargartalebi, A. (2013) Slightly Hydrophobic Silica Nanoparticles for Enhanced Oil Recovery: Interfacial and Rheological Behavior. International Journal of Oil, Gas and Coal Technology, 6, 408-421. https://doi.org/10.1504/IJOGCT.2013.054866

[18] Ahmadi, M.A. (2016) Use of Nanoparticles to Improve the Performance of Sodium Dodecyl Sulfate Flooding in a Sandstone Reservoir. The European Physical Journal Plus, 131, 435. https://doi.org/10.1140/epjp/i2016-16435-5

[19] Goshtasp, C. and Luky, H. (2016) A Review on Applications of Nanotechnology in the Enhanced Oil Recovery Part B: Effects of Nanoparticles on Flooding. International Nano Letters, 6, 1-10. https://doi.org/10.1007/s40089-015-0170-7

[20] William, A.D. and Erica, J.W. (1999) Adsorption of Hexadecyltrimethylammonium Bromide to Mica: Nanometer-Scale Study of Binding-Site Competition Effects. Langmuir, 15, 160-168. https://doi.org/10.1021/la9710942

[21] Rowaida, K.S.K. (2013) Selective Removal and Inactivation of Bacteria by Nanoparticle Composites Prepared by Surface Modification of Montmorillonite with Quaternary Ammonium Compounds. World Journal of Microbiology and Biotechnology, 29, 1839-1850. https://doi.org/10.1007/s11274-013-1346-9

[22] Hou, B.F., Wang, Y.F., Cao, X.L., et al. (2016) Surfactant-Induced Wettability Alteration of Oil-Wet Sandstone Surface: Mechanisms and Its Effect on Oil Recovery. Journal of Surfactants and Detergents, 19, 315-324. https://doi.org/10.1007/s11743-015-1770-y

[23] Salehi, M., Johnson, S.J. and Liang, J.T. (2008) Mechanistic Study of Wettability Alteration Using Surfactants with Applications in Naturally Fractured Reservoirs. Langmuir, 24, 14099-14107. https://doi.org/10.1021/la802464u

[24] Standnes, D.C. and Austad, T. (2000) Wettability Alteration in Chalk: 2. Mechanism for Wettability Alteration from Oil-Wet to Water-Wet Using Surfactants. Journal of Petroleum Science and Engineering, 28, 123. https://doi.org/10.1016/S0920-4105(00)00084-X

[25] Gupta, R. and Mohanty, K. (2011) Wettability Alteration Mechanism for Oil Recovery from Fractured Carbonate Rocks. Transport in Porous Media, 87, 635-652. https://doi.org/10.1007/s11242-010-9706-5

[26] Grosmaire, L., Chorro, M., Chorro, C., et al. (2001) Calorimetric Investigations of Gemini and Conventional Cationic Surfactants at Two Silica-Solution Interfaces. Thermochimica Acta, 379, 261-268. https://doi.org/10.1016/S0040-6031(01)00624-4

[27] Zana, R. (2000) Quaternary Ammonium Bromide Surfactant Oligomers in Aqueous 
Solution: Self-Association and Microstructure. Langmuir, 16, 141-148. https://doi.org/10.1021/la990645g

[28] Qi, L.Y., Liao, W.S. and Bi, Z.H. (2007) Adsorption of Conventional and Gemini Cationic Surfactants in Nonswelling and Swelling Layer Silicate. Colloids and Surfaces A: Physicochemical and Engineering Aspects, 302, 568-572. https://doi.org/10.1016/j.colsurfa.2007.03.035

[29] Bera, A., Kumar, T., Ojha, K. and Mandal, A. (2013) Adsorption of Surfactants on Sand Surface in Enhanced Oil Recovery: Isotherms, Kinetics and Thermodynamic Studies. Applied Surface Science, 284, 87-99. https://doi.org/10.1016/j.apsusc.2013.07.029

[30] Zheng, Y.C., Huang, Q.S. and Mei, P. (2009) Effect of Inorganic Salts on the Properties of Gemini Surfactant and Its Synergistic Effect. Journal of Oil and Gas Technology, 31, 145. (In Chinese)

[31] Cui, Z.G., Shi, K.Z., Cui, Y.Z. and Binks, B.P. (2008) Double Phase Inversion of Emulsions Stabilized by a Mixture of $\mathrm{CaCO}_{3}$ Nanoparticles and Sodium Dodecyl Sulfate. Colloids and Surfaces A, 329, 67. https://doi.org/10.1016/j.colsurfa.2008.06.049

[32] Yao, T.Y., Yf, Y. and Li, J.S. (2008) Study on Adsorption and Enthalpy Change of Cationic Surfactants on Different Sandstone Surfaces. Oil Drilling and Production Technology, 30, 82. (In Chinese)

[33] Lindheimer, M. and Partyka, S. (1995) Calorimetric Evidence for the Similarity between the Mechanisms of Cationic and Anionic Surfactant Adsorption on Oppositely Charged Crystalline Oxide Surfaces. Progress in Colloid and Polymer Science, 98, 303.

[34] Esumi, K., Goino, M. and Koide, Y. (1996) Adsorption and Adsolubilization by Monomeric, Dimeric, or Trimericquaternary Ammonium Surfactant at Silica/Water Interface. Journal of Colloid and Interface Science, 183, 539-545. https://doi.org/10.1006/jcis.1996.0577

[35] Upadhyaya, A., Acosta, E.J., Scamehorn, J.F. and Sabatini, D.A. (2007) Adsorption of Anionic-Cationic Surfactant Mixtures on Metal Oxide Surfaces. Journal of Surfactants and Detergents, 10, 269-277. https://doi.org/10.1007/s11743-007-1045-3 